\title{
FLIBE BLANKET CONCEPT FOR TRANSMUTING TRANSURANIC ELEMENTS AND LONG LIVED FISSION PRODUCTS
}

The submitted manuscript has been created by the University of Chicago as Operator of Argonne National Laboratory ("Argonne") under Contract No. W-31-109-ENG-38 with the U.S. Department of Energy. The U.S. Government retains for itself, and others acting on its behalf, a paid-up, nonexclusive, irrevocable worldwide license in said article to reproduce, prepare derivative works, distribute copies to the public, and pertorm publicly and display publicly, by or on behaif of the Government.

A Molten salt (Flibe) fusion blanket concept has been developed to solve the disposition problems of the spent nuclear fuel and the transuranic elements. This blanket concept can achieve the top rated solution, the complete elimination of the transuranic elements and the long-lived fission products. Small driven fusion devices with low neutron wall loading and low neutron fluence can perform this function. A 344-MW integrated fusion power from D-T plasmas for thirty years with an availability factor of 0.75 can dispose of 70,000 tons of the US inventory of spent nuclear fuel generated up to the year 2015. In addition, the utilization of this blanket concept eliminates the need for a geological repository site, which is a major advantage. This application provides an excellent opportunity to develop and to enhance the public acceptance of the fusion energy for the future. The energy from the transmutation process is utilized to produce revenue. Flibe, lithium-lead eutectic, and liquid lead are possible candidates. The liquid blankets have several features, which are suited for this application. It can operate at constant thermal power without interruption for refueling by adjusting the concentration of the transuranic elements and lithium-6. These liquids operate at low-pressure, which reduces the primary stresses in the structure material. Development and fabrication costs of solid transuranic materials are eliminated. Burnup limit of the transuranic elements due to radiation effects is eliminated. Heat is generated within the liquid, which simplifies the heat removal process without producing thermal stresses. These blanket concepts have large negative temperature coefficient with respect to the blanket reactivity, which enhances the safety performance. These liquids are chemically and thermally stable under irradiation conditions, which minimize the radioactive waste volume. The operational record of the Molten Salt Breeder Reactor with Flibe was very successful, which established the technical bases for this application. This paper provides the technical analyses and the performance of the Flibe blanket concept as an example of this class of blankets.

\section{INTRODUCTION}

The disposal of the transuranic elements and the longlived fission products represents a major problem under investigation by the international scientific community to identify the most promising solutions. Different fusion options ${ }^{1,2.3}$ were considered to resolve this problem where the analyses showed the fusion potential to perform this function. The investigation of this paper concentrated on achieving the top rated solution for the problem, the elimination goal. This solution requires complete elimination for the transuranic elements and the long-lived fission products without leftovers that require geological repository. To achieve this goal, blankets with liquid carriers for the transuranic elements were considered. As an example of this class of blankets, analysis was performed for the Flibe blanket concept to define its performance and to size the required fusion system for solving the US spent nuclear fuel problem. Special attention was given to the use of existing technologies to avoid expensive $R \& D$ and to provide near term solution. This paper summarizes the work performed and the main results.

\section{Background}

Fusion can provide a complete and attractive solution for the disposition problems of the spent nuclear fuel and the transuranic elements. In addition, the fusion technical requirements for this function are very modest, as will be seen from the analysis. This will provide an excellent opportunity to develop fusion as an energy source for the future while providing a near term solution for these problems.

In the United States, the inventory of the spent nuclear fuel from the commercial power plants will reach 70,000 tons by the year of 2015. In this spent nuclear fuel, a small fraction of the uranium fuel is utilized for energy production, producing fission products and transuranic elements. This inventory of spent nuclear fuel consists of about 67,000 tons of uranium, 600 tons of transuranic elements, and 2400 tons of fission products. Most of the fission products have relatively short half-lives, tens of years. To dispose the spent nuclear fuel, uranium, fission products, long lived fission products ( $\mathrm{Tc}^{99}, \mathrm{I}^{129}, \mathrm{etc}$ ), and transuranic elements are separated. Uranium can be recycled in fresh fuel or disposed as low-level radioactive waste (Class-C waste). The fission products will be processed for disposal in a temporary repository to decay. The long-lived fission products will be fabricated into fission product targets for transmutation in fusion reactors utilizing the neutron leakage from the fusion blanket. The 


\section{DISCLAIMER}

This report was prepared as an account of work sponsored by an agency of the United States Government. Neither the United States Government nor any agency thereof, nor any of their employees, make any warranty, express or implied, or assumes any legal liability or responsibility for the accuracy, completeness, or usefulness of any information, apparatus, product, or process disclosed, or represents that its use would not infringe privately owned rights. Reference herein to any specific commercial product, process, or service by trade name, trademark, manufacturer, or otherwise does not necessarily constitute or imply its endorsement, recommendation, or favoring by the United States Government or any agency thereof. The views and opinions of authors expressed herein do not necessarily state or reflect those of the United States Government or any agency thereof. 


\section{DISCLAIMER}

Portions of this document may be illegible in electronic image products. Images are produced from the best available original document. 
transuranic elements will be fissioned in fusion blankets where energy will be produced to generate revenue.

Also, fusion option can be used to dispose of the current inventory of transuranic elements by utilizing its energy content and transmuting its long lived fission products, which represents a complete and attractive solution for this problem. The current inventory is about 135 tons of transuranic elements processed from spent nuclear fuel, about 1400 tons of highly enriched uranium, and 100 to 260 tons of plutonium.

\section{FUSION NEUTRONS}

Fusion neutrons from D-T plasma have several characteristics that result in attractive performance for such application. The spatial distribution reduces the power density in the blanket materials, which facilitates the heat removal process. Most of the fusion energy, $\sim 80 \%$, are carried by the D-T neutrons that reduces the first wall surface heat flux of the fusion blanket. The high neutron energy enhances the neutron multiplication through $(n, 2 n)$, $(n, 3 n)$, and the fast fission reactions, which increases the disposal rate of the transuranic elements and the transmutation rate of the long-lived fission products. This combination of features is unique for fusion neutrons relative to other possible neutron sources, point sources or low energy distributed sources, which enhances the performance of the fusion solution for this application.

\section{FUSION BLANKET CONCEPTS}

Fast neutrons have neutronics advantages for transmuting the transuranic elements relative to thermal neutrons including higher fission reaction rate per neutron, efficient neutron production and utilization with high concentration of fission products, and lower probability for generating high actinides. The thermalized neutron leakage from the blanket is utilized for transmuting the long-lived fission products. These advantages favor fusion blankets with fast neutron spectrum for achieving high performance for this application. In addition, the large change in the blanket thermal output due to the concentration change of the transuranic elements, and the desire to operate at constant output power require the use of fusion blanket concepts capable of continuously mixing and adjusting the concentration of the transuranic elements. Also, the possibility of removing fission products during operation to increase the neutron utilization lead to the consideration of fusion blankets with mobile carrier for the transuranic elements. Molten salts and liquid metal eutectics are the preferred carriers that result in a blanket operation with fast neutron spectrum. Aqueous carriers are excluded because of its neutron slowing down characteristics. Solid carrier is another possibility, but it is not considered in this analysis because of the fabrication and reprocessing requirements. Molten fuel salt ${ }^{3,6}$ was developed and used for fission reactors. Flibe molten salt $\left(\mathrm{Li}_{2} \mathrm{BeF}_{4}\right)$ was selected and used for the Molten Salt Breeder Reactor (MSBR). Molten salt technologies were developed for MSBR in the 1960's, for the fuel cycle of the fast breeder program in the 1990's, and for decommissioning the molten fuel salt of the MSBR in the 1990's. Also, fusion reactors are considering Flibe as a tritium breeder and coolant for magnetic and inertial confinement concepts. Flibe molten salt can be used as tritium breeder, transuranic carrier, neutron multiplier, and coolant for the fusion blankets.

Lithium-Lead eutectic (17Li-83Pb) is under development as a breeder and coolant for fusion reactors ${ }^{7,8}$. Lithium-Lead eutectic posses several attractive features including low melting point $\left(235^{\circ} \mathrm{C}\right)$, good neutron multiplication performance, low parasitic absorption cross section, acceptable material compatibility with the steel structure, and an acceptable safety performance. Similar to Flibe, Lithium-Lead eutectic can be used as a carrier for the transuranic elements. For this application, the lithium-lead has the advantage of less slowing down characteristics for the fusion neutrons due to the absence of beryllium, which improves the blanket performance. Both carriers can use a continuous feed of transuranic elements, which allows the blanket to maintain a constant output power.

Solid fusion blankets require frequent material shuffling and replacement to readjust the spatial distribution of the transuranic elements for maintaining a minimum output power. The replaced materials need processing to separate the unused transuranic elements, the fission products, and the long-lived fission products for recycling in the system. For these reasons, this investigation concentrated on the liquid blankets. In addition, liquid fusion blankets possess several unique attractive features, which result in excellent performance for this application.

- The liquid blanket can operate at constant output power by adjusting the liquid composition (transuranic elements and lithium-6), which is an essential requirement for power generation.

- The blanket mode of operation achieves the elimination goal, which is the top rated option for this application.

- Both, Flibe and lithium-lead liquids require low-pressure system. This reduces the primary stresses in the blanket structure, which improves the blanket design and its performance.

- Development and fabrication costs of the solid transuranic materials are eliminated. This also represents a significant attractive feature for the security of the transuranic materials.

- Burnup limit for the transuranic elements due to radiation effects is eliminated, which permits achieving the elimination goal.

- Heat is generated within the liquid, which simplifies the heat removal process without generating thermal stresses.

RECEIVED

DEC $0 \& 2000$ 
- Both. Flibe and lithium-lead liquids have large negative temperature coefficient with respect to the blanket reactivity, which enhances the safety performance.

- Both, Flibe and lithium-lead liquids are chemically and thermally stable under irradiation conditions, which minimizes the radioactive waste volume and permits achieving the elimination goal.

- The operational record of the MSBR was very successful, which minimizes the technical risk using this option.

- Uranium, thorium, and plutonium were used as source of power in the operation of the MSBR that established the technical database for this selection.

The operation of the liquid blankets requires chemical control methods to insure compatibility with the structural material and to reduce the tritium permeation rate from the system to an acceptable level. Several methods were successfully tested, however these methods have to be reassessed for operation with magnetic field and fission products.

\section{FLIBE MOLTEN SALT BLANKET CONCEPT}

Flibe was characterized for the MSBR in 1960's including the physical properties, the corrosion issue, the chemical processing, and the solubility of the fuel compounds and the fission products in the salt. ${ }^{7,9}$ The salt properties used in the analysis are summarized in Table $\mathrm{I}$. $\mathrm{UF}_{4}, \mathrm{ThF}_{4}$, and $\mathrm{PuF}_{3}$ are the compounds selected for the MSBR. For example, $\mathrm{PuF}_{3}$ is a solid with a density of 9.32 $\mathrm{g} / \mathrm{cm}^{3}$ and it has a melting point of $1425^{\circ} \mathrm{C}$. The solubility of $\mathrm{PuF}_{3}$ in Flibe was measured ${ }^{9}$ for composition ranging in $\mathrm{BeF}_{2}$ from 28.7 to 48.3 mole in the temperature range of 450 to $650^{\circ} \mathrm{C}$. In the analysis, the $\mathrm{PuF}_{3}$ weight fraction in the salt was varied in the range of 0.0025 to $0.0275(0.084$ to 0.94 Mole \%) reflecting the experimental data.

Table I

The Main Physical Properties of Flibe $\left(\mathrm{Li}_{2} \mathrm{BeF}_{4}\right)$.

\begin{tabular}{|c|c|}
\hline Melting point, ${ }^{\circ} \mathrm{C}$ & 459.1 \\
\hline Thermal conductivity, $\mathrm{W} / \mathrm{cm} .{ }^{\circ} \mathrm{C}$ & 0.010 \\
\hline Viscosity, centipoises & $0.116 \exp \left[3755 / \mathrm{T}\left({ }^{\circ} \mathrm{k}\right)\right]$ \\
\hline Electrical conductivity at 500 , oh & $\mathrm{mm}^{-1} \mathrm{~cm}^{-1}$ \\
\hline Heat capacity, cal/g. ${ }^{\circ} \mathrm{C}$ & 0.57 \\
\hline Density, $\mathrm{g} / \mathrm{cm}^{3}$ & $2.214-4.2 \times 10^{-4} \mathrm{~T}\left({ }^{\circ} \mathrm{C}\right)$ \\
\hline
\end{tabular}

A poloidal blanket configuration is considered where the inlet and the outlet manifolds are located at the top section of the reactor ${ }^{10}$. The salt coolant is introduced first to the front section of the blanket to remove the surface heat flux from first wall. Then, the flow direction changes at the bottom to leave the blanket at the top. This tlow pattern simplifies the manifold system.
At the startup, it is foreseen to operate the blanket without transuranic elements to confirm and calibrate the operation of the different reactor systems. This mode of operation reduces the shielding capability of the blanket due to the absence of the neutron absorber, the transuranic elements. Therefore, the blanket performance was first defined with pure Flibe salt as a function of the blanket radial thickness. The Flibe zone thickness was varied from 0.2 to $0.6 \mathrm{~m}$. A $0.5-\mathrm{m}$ Flibe zone thickness is required to reduce the energy deposition in the shield to $\sim 4 \%$ of the total blanket and shield energy deposition. At this blanket thickness, the other performance parameters, the tritiumbreeding ratio (TBR) and the blanket energy multiplication are very close to the saturation values.

The second step defined the blanket performance with $\mathrm{PuF}_{3}$ dissolved in the Flibe. The $\mathrm{PuF}_{3}$ weight fraction varied parametrically in the range of 0.0025 to 0.0275 , which is consistent with the experimental results. The results show that the blanket performance parameters (Blanket energy multiplication factor, Total energy multiplication factor, Local tritium breeding ratio, Shield energy fraction, Fission reactions per D-T neutron, Transmutation rate, $\mathrm{kg} / \mathrm{MW} . \mathrm{y}$ ) change monotonically in this range. As the $\mathrm{PuF}_{3}$ concentration in the Flibe salt increases, the blanket performance parameters are improved as shown in Fig. 1. At the highest $\mathrm{PuF}_{3}$ concentration, the plutonium transmutation rate is $4.4 \mathrm{~kg} / \mathrm{MW}$.y of fusion power. The corresponding tritium-breeding ratio and the blanket energy multiplication factor are 2.2 and 15.3, respectively. This high tritium-breeding ratio indicates that the lithium- 6 concentration can be reduced to increase the transmutation rate and to reduce the tritium-breeding ratio.

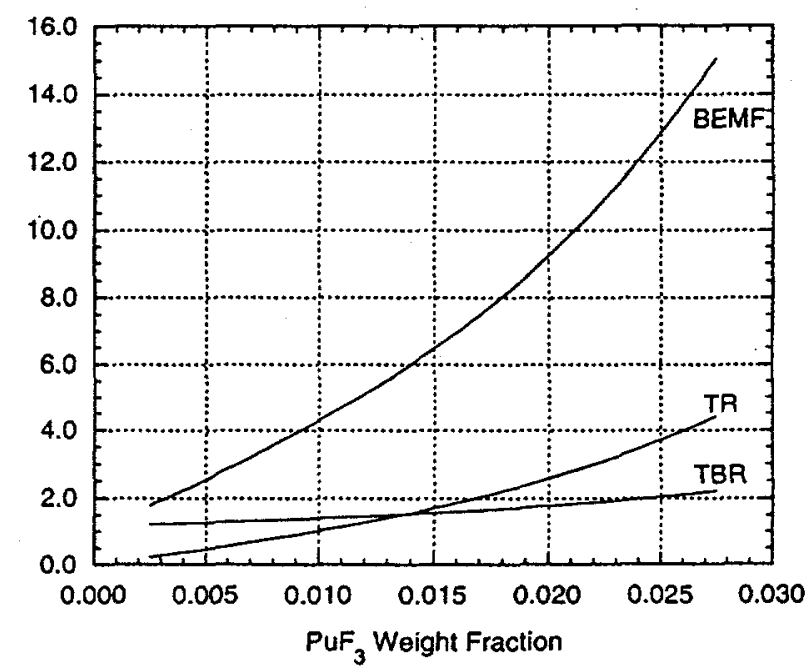

Fig. 1. Blanket energy multiplication factor (BEMF), transmutation rate ( $T R-k g / M W . y)$, and tritium breeding ratio (TBR) as function of the $\mathrm{PuF}_{3}$ weight fraction in the Flibe molten salt. 
Then, the blanket performance analyzed parametrically as a function of the lithium- 6 concentration in the range of 2.5 to $7.5 \%$ (natural lithium) with constant $\mathrm{PuF}_{3}$ concentration. As the lithium- 6 concentration decreases, the blanket performance parameters improve monotonically as shown in Fig. 2. The transmutation rate changes from 3.4 to $48 \mathrm{~kg} / \mathrm{MW} . \mathrm{y}$ as the lithium-6 concentration varies from $7.5 \%$ to $2.5 \%$. However, the local tritium-breeding ratio is also increased to 10.8 for the $2.5 \%$ lithium- 6 concentration. This suggests that the $2.5 \%$ lithium- 6 concentration is high and it can be reduced further to increase the transmutation rate. Also, the $\mathrm{PuF}_{3}$ concentration can be reduced for the same transmutation rate, which enhances the safety characteristics. The blanket energy multiplication factor reaches 160 , which provides good revenue to recover the transmutation cost.

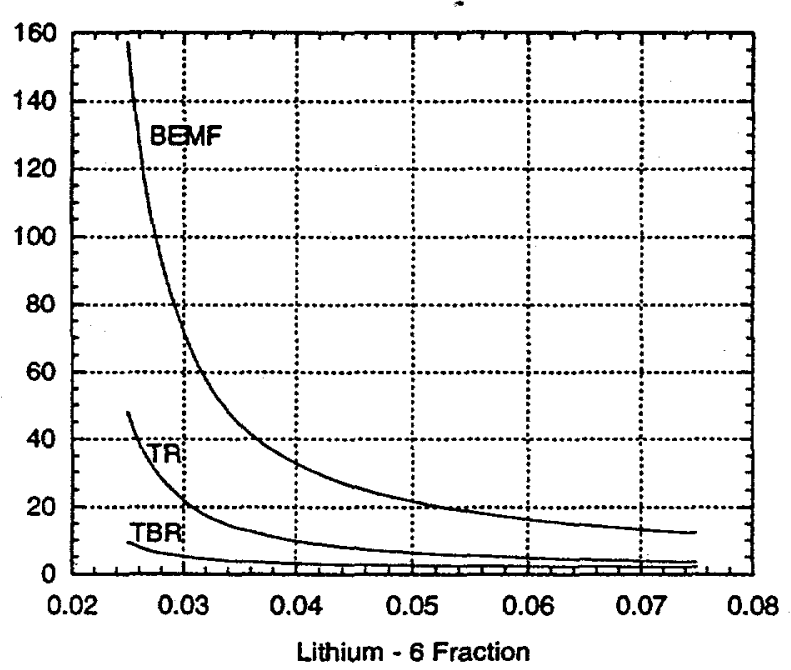

Fig. 2. Blanket energy multiplication factor (BEMF), transmutation rate (TR - $\mathrm{kg} / \mathrm{MW} . \mathrm{y}$ ), and tritium breeding ratio (TBR) as function of of the lithium - 6 fraction.

Then the blanket configuration was analyzed with $100 \%$ lithium-7 and the $\mathrm{PuF}_{3}$ weight fraction value in Flibe was iterated to get $\mathrm{K}_{\text {eff }}$ of 0.98 for sub-critical operation. Table II gives the performance parameters for such blanket configuration. The plutonium transmutation rate is 72.6 $\mathrm{kg} / \mathrm{MW}$.y of fusion power, which is quite satisfactory. The blanket energy multiplication and the energy fraction in the shield are 242.6 and 0.018 . However, the tritium-breeding ratio of this blanket is 0.488 , which is not adequate for tritium self-sufficiency. Therefore, a very small concentration of lithium- 6 is required for a small operating period to accumulate enough tritium for self-sufficiency. The lithium- 6 concentration changed to $0.25 \%$ and the $\mathrm{PuF}_{3}$ concentration value was adjusted to get $\mathrm{K}_{\text {eff }}$ of 0.98 . The resulting performance parameters are also given in Table II, which are quite satisfactory. The analyses show that lithium- 6 act as a burnable absorber. As its concentration increases, the required concentration of $\mathrm{PuF}_{3}$ increases to maintain the same $K_{\text {eff }}$ value. The lithium- 6 concentration decreases as the reactor operates as well as the $\mathrm{PuF}_{3}$ concentration. The tritium-breeding ratio with low lithium- 6 concentration is very high, which allows the reactor to operate without lithium- 6 for extended periods. Since the accumulated tritium will be adequate to insure tritium self-sufficiency. It is possible to use a lower value and consequently a lower $\mathrm{PuF}_{3}$ concentration. A system optimization is required to define the lithium- 6 and $\mathrm{PuF}_{3}$ concentrations taken into consideration economic, safety, and material issues.

Table II

Blanket Configuration and Main Parameters.

\begin{tabular}{|c|c|c|}
\hline \multicolumn{3}{|c|}{ Blanket configuration } \\
\hline \multicolumn{3}{|c|}{$\begin{array}{r}\text { Type } 316 \text { stainless steel }-0.5 \mathrm{~cm} \text { thick } \\
\text { Flibe with } \mathrm{PuF}_{3}-50 \mathrm{~cm} \\
\text { Type } 316 \text { stainless steel }-1.0 \mathrm{~cm} \text { thick } \\
\text { Type } 316 \text { Austenitic steel and } 20 \% \mathrm{H}_{2} \mathrm{O} \text { ) }\end{array}$} \\
\hline \multicolumn{3}{|c|}{ Blanket parameters } \\
\hline Blanket thickness, $\mathrm{cm}$ & 51.5 & 51.5 \\
\hline Lithium - 6 fraction & 0.0 & 0.0025 \\
\hline $\mathrm{PuF}_{3}$ weight fraction & 0.00051 & 0.0056 \\
\hline Blanket energy multiplication factor & 242.6 & 264.0 \\
\hline Local tritium breeding ratio & 0.488 & 10.74 \\
\hline Transmutation rate, $\mathrm{kg} / \mathrm{MW} . \mathrm{y}$ & 72.56 & 79.69 \\
\hline Shield energy fraction & 0.035 & 0.025 \\
\hline Neutron wall loading, $\mathrm{MW} / \mathrm{m}^{2}$ & 0.1 & 0.1 \\
\hline Blanket poloidal length, $m$ & 5 & \\
\hline Surface heat flux, $\mathrm{MW} / \mathrm{m}^{2}$ & 0.025 & 0.025 \\
\hline Flibe temperature change, ${ }^{\circ} \mathrm{C}$ & 100 & 100 \\
\hline $\begin{array}{l}\text { Flibe velocity, } \mathrm{m} / \mathrm{s} \\
\text { Flibe inlet and outlet from the top }\end{array}$ & 1.06 & 1.15 \\
\hline
\end{tabular}

\section{FUSION POWER REQUIREMENTS FOR DISPOSING OF THE US INVENTORY OF THE SPENT NUCLEAR FUEL}

The total amount of transuranic elements in the US inventory of the spent nuclear fuel will reach 600 tons by the year 2015. A molten salt fusion blanket with $k_{\text {eff }}$ of 0.98 can transmute $\sim 79.7 \mathrm{~kg}$ of transuranic elements per MW.y of fusion power as shown in Table II. To transmute the total US inventory, a fusion fluence of $7528 \mathrm{MW} . \mathrm{y}$ is required. A 334-MW of fusion power from several devices can provide such fluence over 30 years assuming an availability factor of 0.75 . These fusion devices can be constructed 
based on the current technology with driven plasma, which provides near term solution for the spent nuclear fuel disposition and an opportunity to develop fusion energy.

In addition, the analysis of the molten salt blanket shows that the transmutation rate and the blanket output power can be adjusted over a wide range, which provides a large flexibility to choose the fusion parameters including the fusion power level. Such flexibility is important for the long-term development of fusion energy. For example, a larger fusion power can be used if it is required for the development of the plasma physics or the reactor technology. In this case, the concentration of the lithium- 6 and the transuranic elements in the liquid carrier can be adjusted to achieve the target values of output power, transmutation rate, and tritium breeding ratio. Also, the number of the long-lived fission product targets inserted in the fusion reactor for transmutation can be adjusted to regulate the thermal output as required.

\section{CONCLUSIONS}

The analyses of this paper show that fusion can provide a complete and attractive solution for the disposition problems of the spent nuclear fuel and the transuranic elements. Fusion blankets with liquid carrier for the transuranic elements and the uranium isotopes achieve the elimination goal, which is the top rated solution for these problems. In subcritical system, this type of blankets has a transmutation rate up to $80 \mathrm{~kg} / \mathrm{MW}$.y of fusion power. The energy from the transmutation process produces revenue for the system. In addition, this solution eliminates the need for a geological repository, which is a major advantage. Flibe molten salt and lithium-lead eutectic are identified as the most promising liquids for this application where fusion blankets using both materials are under development for future fusion systems.

Meanwhile, this application will provide an excellent opportunity to develop the fusion energy for the future by building small fusion devices. A 334-MW of fusion power from several devices for thirty years with an availability factor of 0.75 can transmute all the transuranic elements and the long-lived fission products in the 70,000 tons of the US inventory of spent nuclear fuel generated up to the year 2015. These devices will have an operating flexibility with respect to the fusion power by adjusting the blanket parameters to maintain an acceptable output power. This operating flexibility will provide a mechanism to develop the fusion energy for the future.

Further analyses and studies are needed to develop such system considering previous work including nonfusion options. System definition, identification of the technical issues that require resolution, schedule and plan to resolve these issues, total cost estimate, and comparison with the other options under consideration need to be included in these studies. These studies will emphasize the utilization of the existing technologies to minimize the R\&D cost and the schedule to complete the disposition process.

\section{ACKNOWLEDGMENTS}

Work supported by the Office of Fusion Energy Sciences, U. S. Department of Energy, under Contract No. W-31-109ENG-38.

\section{REFERENCES}

1. T. A. Parish and J. W. Davidson, "Reduction in the Toxocoty of Fission Product Wastes Through Transmutation with Deutrium-Tritium Fusion Neutrons," Nuclear Technology, Vol. 47, February 1980.

2. W. M. Stacey, et al., "A Transmutation Facility for Weapons-Grade Plutonium Disposition Based on a Tokamak Fusion Neutron Source," Fusion Technology, Vol. 27, May 1995.

3. E. T. Cheng and R. J. Cerbone, "Prospect of Nuclear Waste Transmutation and Power Production in Fusion Reactors," Fusion Technology Vol. 30, December 1996.

4. Committee on International Security and Arms Control, "Management and Disposition of Excess Weapons Plutonium," National Academy of Science, Washington, D. C., National Academy Press, 1995.

5. J. R. McWherter, "Molten Salt Breeder Experiment Design Bases," Oak Ridge National Laboratory Report, ORNL-TM-3177, November 1970.

6. R. E. Thoma, "Chemical Aspects of MSRE Operation," Oak Ridge National Laboratory Report, ORNL-4658, December 1971.

7. D.L. Smith, et al., Blanket comparison and selection study - Final report, Árgonne National Laboratory report, ANL/FPP-84-1 (1984).

8. L. Giancarli, G.Benamati, M. Fütterer, G. Marbach, C. Nardi, and J. Reimann, "Development of the EU WaterCooled PB-17Li Blanket," Fusion Engineering and Design 39-40 (1998).

9. R. E. Thoma, "Chemical Feasibility of Fueling Molten Salt Reactors with $\mathrm{PuF}_{3}$," Oak Ridge National Laboratory Report, ORNL-TM-2256, October 1968.

10. Y. Gohar, "Fusion Option to Dispose of Spent Nuclear Fuel and Transuranic Elements," Argonne National Laboratory Report, ANL/TD/TM00-09, January 2000. 